\title{
Prioritization of Supply Chain Risks in Indian Manufacturing Context
}

\author{
Harish Babu, Prabhas Bhardwaj, Anil Kumar Agrawal
}

\begin{abstract}
Supply chain risk management is an important aspect of every organisation. Each supply chain risks has a different effect on the performance of supply chain, due to the various characteristics of supply chain risk variables like level of impact, probability of occurrence, cost of anticipation. Therefore, it is very important for supply chain mangers to analyse and evaluate the relative importance of each risk variable to proactively plan for them and determine their priority. This study aims to evaluate and prioritize of the major supply chain risks, by using AHP methodology. Indian manufacturing organisation needs to pay conspicuous attention in the field of supply chain risk management and I hope that this research article would provide additional dimensions in the same context.
\end{abstract}

Keywords: Analytical Hierarchy Process, Risk Management, Risk Modelling, Risk Prioritization, Supply Chain Risk Management (SCRM), Indian manufacturing organisation, Supply risks, Demand Risks.

\section{INTRODUCTION}

Indian manufacturing organisation are under immense pressure due to supply chain disruption, globalization, rapid change in technology and competition. It is essential for Indian manufacturing organisation to assess their supply chain and adapt proactive planning in order to anticipate the supply chain risks. Modern supply chains are very complex, which makes them more vulnerable. Due to this complexity of supply chain, Indian manufacturing organisations faces different types of risks associated with their supply chain network. The unpredictable nature, improper evaluation of risks, leads to adverse effect on the performance of supply chain. Therefore, assessment of supply chain risks is an important activity for organisations. The main problem of supply chain managers is how to understand and identify the significant risk associated with their supply chain and how to evaluate or prioritize these risks.

[1] emphasis on the catastrophic/environmental risk and proposed a process for supply chain managers, to help in creation and selection of appropriate strategy to anticipate the

Revised Manuscript Received on April 25, 2020.

* Correspondence Author

Harish Babu*, Deptt. of Mechanical Engineering, Indian Institute of Technology (BHU), Varanasi, Uttar Pradesh, India..

Prabhas Bhardwaj, Deptt. of Mechanical Engineering, Indian Institute of Technology (BHU), Varanasi, Uttar Pradesh, India.

Anil Kumar Agrawal, Deptt. of Mechanical Engineering, Indian Institute of Technology (BHU), Varanasi, Uttar Pradesh, India.

(C) The Authors. Published by Blue Eyes Intelligence Engineering and Sciences Publication (BEIESP). This is an open access article under the CC BY-NC-ND license (http://creativecommons.org/licenses/by-nc-nd/4.0/) impact of catastrophic events. [2] conducted four case studies for modeling risk by using AHP approach and provided a guideline for decision-makers to select the appropriate method while dealing with risk or uncertainty. [3] identified and explained various risks factors associated with automotive manufacturers. By using the multi-criteria scoring method, they developed a model for assessment and monitoring of risk factors. [4] emphasis on evaluations of the impact and the cause-effect relationship of risk indicators and proposed an AHP model to prioritize supply chain risk indicator.

AHP method is a very useful tool to identify the priorities and impact analysis of these risks. To understand and implement the SCRM Process, several questions may arise for supply chain managers like: What are the major supply chain risks? How to forecast them? How to evaluate the impact of risk? How to prioritize them? A structured SCRM-AHP model can answer these questions. [5] identified and analysed the impact of the six major critical risk criteria and their 28 sub-criteria, on the supply chain and ranked these criteria and sub-criteria by using AHP methodology.

The main objective of this research paper is to develop a decision model, for assessment and prioritize the risks of the supply chain. To achieve the desired objective, analytic hierarchy process (AHP), a popular multi-criteria decision making (MCDM) tool used as a solution methodology. This model divided into three levels constituting goal, criteria and alternatives. [6] also discussed various risks variables of supply chain and describe their interrelationships by using ISM-MICMAC approach. From the literature review, the major risk variables, their sub-risk variables, and anticipation strategies, associated with Indian manufacturing organisations were identified and narrowed down them with the help of experts. Literature review on SCRM indicated that many models has been reported on SCRM and their implementation in various industries but only a few research studies available, related to prioritization and evaluation of risks in context to Indian manufacturing organisations. There are several supply chain risks associated with the Indian manufacturing organisations, but due to resource constraint, it is not feasible for them to give same attention to all risk variables. Thus, it creates a strong and justifiable need to identify, assess, and prioritize the risk variables to successfully implementation of SCRM in the Indian manufacturing context.

The main objectives of the present study are: to identify the significant risk variables of Indian manufacturing organisation;

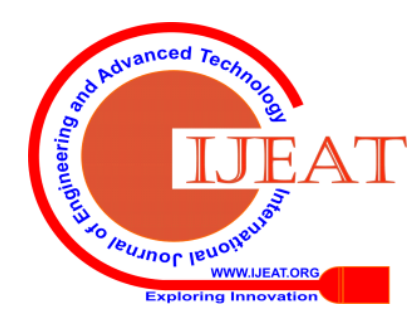




\section{Prioritization of Supply Chain Risks in Indian Manufacturing Context}

and to determine the relative importance of these risk variables so that Indian manufacturing organisation can evaluate their supply chain risks and allocate their resources to efficiently implement SCRM. Supply chain risk management is a subjective concept and it totally depends upon the availability, reliability, and quality of primary data.

Due to several types of risk categories and sub-risk categories, it is difficult to identify the exact methodology and model to analyse the risk. AHP method is a multi-criteria decision-making tool and widely accepted among the researchers to rank the alternatives [7].

This remainder paper is organised as follows: Section-2 consists of a literature review on supply chain risk management and AHP approach in this area. Section-3, described the supply chain risks and proposed framework for prioritizing the supply chain risk variables associated with Indian Manufacturing Organisations. Section-4 describes the research methodology along with a case study. Finally, Section-5 summarizes the research and findings gained by the above methodology, along with the scope of future research.

\section{LITERATURE REVIEW}

This research work starts with a literature review on supply chain risk management. For the literature review, last 15 years of research papers were collected from reputed publishers like Elsevier, Taylor and Francis, John Wiley and Sons, Science direct and Inderscience. Supply Chain Risk Management (SCRM), Supply risk, SCRM strategies, AHP approach, prioritization of risk, etc., keywords are used to search related articles. This research basically deals with risks associated with Indian manufacturing supply chains. The word 'Risk' is defined by the British Standard Institute (BS4778:1991) as "combination of probability or frequency of occurrence of a defined hazard and magnitude of the occurrence" [8]. Supply chain risks can be classified into two major categories; internal risks and external risk. Other criteria for classification may be based on their impact, based on controllable/uncontrollable and based on their occurrence. External risk refers to natural disasters (e.g., Tsunami, flood, and earthquake) and man-made risks (e.g., terrorism, volatile financial market, war, etc.). Internal Risk refers to the risk associated with the internal environment of supply chain or the risk, which is directly associated with the supplier, manufacturer, distributor, and consumer. Further, the internal risk is classified into four major sub-categories namely; supply risk, process risk, transportation risk, demand risk, information technology risk and delay risk; and the external risk can be understood as environmental risk [9]. These risks may lead to the various potential disruption at any stage of the supply chain and affect the whole supply chain, from downstream to upstream. Hence, to proactively anticipate these risks, SCRM is essential for any organisation [10].

From the literature review, it is found that some models were proposed by researchers, on Supply Chain risk management. But only a few SCRM-Models are available based on Indian manufacturing context. [11] developed a model for SCRM, which is helpful for the supply chain managers to understand the various type of risks associated with supply chain, their interrelationship and to find the best strategy to anticipate them. [12] explored the supply chain risks and risk management strategies, related to the global supply chain. They conducted in-depth interviews and group discussions with global supply chain managers and identified six risk management strategies, which are avoidance, hedging, control/share/transfer, speculation, security, and postponement. Based on these identified risks and risk management strategies, they proposed a decision-making model, this model provides a guideline for the selection of best risk management strategy to the supply chain managers. Based on the literature review available on SCRM, [13] defined the SCRM process. These steps are as following; step-1 identification and modeling of risks, step-2 assessment of risk and measurement of impact when risks occur, step-3 risk management, step-4 evaluation and monitoring of risk, step-5 feedback and Learning of SCRM process. [14] reviewed several SCRM research papers, published between the year 1995 to 2009. They mainly focused on the financial risk of supply chain and emphasized on the need for quantitative models of SCRM. Five major risk categories namely macro level risk, product/service management risk, supply management risk, demand management risk, and information management risk are identified by [15]. By using Interpretive Structural Modelling (ISM), they developed an SCRM model and conducted a case study on the food manufacturing company to validate this model. [16] also emphasized on the importance of SCRM for Indian companies. They conducted a study on Indian Automobile Industry and found that supply chain risks make them more vulnerable. They conducted a survey on 79 Indian automobile companies and from the supply chain experts of these company's, they collected primary data on SCRM strategies to mitigate the supply chain risks. A stochastic integer linear programming based SCRM model was presented by [17]. This model explained the relationship between risks and their probable impact. This model also prioritizes the supply chain risks to select the mitigation strategy. Pradhan and Routroy (2014) suggested a methodology for the assessment of supply chain risks and also proposed mitigation strategies for these risks. By using cause-effect analysis, they identified major risks associated with manufacturing units and prioritized them with the help of AHP methodology. [18] emphasized on supply chain network risks rather than the firm's risk. They proposed a hierarchical model to define the interrelationships among these risk variables by using the ISM approach. They further classified and quantified the risk variables by using MICMAC analysis.

[19] conducted a study on Green Supply Chain and identified six major risks and twenty-five sub-risks of GSC. They prioritized these risks and sub-risks using fuzzy analytic hierarchy process (fuzzy AHP) and their results reveal that operational risks/process risks are most important risks in GSC. [20] reviewed the literature in SCRM and considered 224 research articles

published between 2003 to 2013 in international journals. Based on literature review, they categorized supply chain risks into three categories namely;

Published By:

Blue Eyes Intelligence Engineering

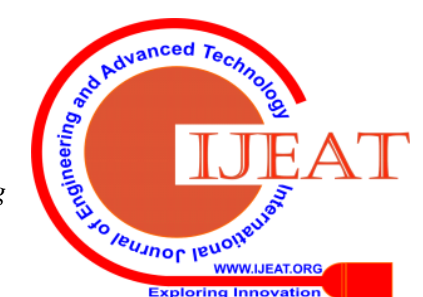


internal risk, external risk, and network-related risk. They review 208 quantitative- and qualitative-based articles on SCRM process and defined SCRM process into four processes namely; Identification, Assessment, Mitigation, and Monitoring. They also confirmed the future need for exploration the

interdependencies and interrelationships among various risk types. A combined approach using AHP and DEMATEL for evaluating success factors in implementation of green supply chain management in Indian manufacturing industries is proposed by [21]. [22] used data envelopment analysis (DEA) and analytic hierarchy process (AHP) methodology to measure the supply chain risk in offshoring Countries. [23] identified Six risk criteria 28 sub-criteria of business continuity management/process and ranked them by using AHP methodology. They found organisational and management risk (OMR)' and sub-criteria namely 'management policies failure' to be the most significant risk to Business Continuity Management. [24] conducted a case study on SCRM and quality aspects of Indian automotive industries. They identified critical risks of supply chain and classified them into three categories. Using the survey method, they prioritized and ranked these supply chain risks. They found process risk and supply risk are the most critical risks of Indian automotive supply chain.

\section{PROBLEM DESCRIPTION}

Globalization, rapid advancement in technology, competition in the market, changes in demand patterns, etc., intensifies the Indian manufacturing organisations and makes their supply chains longer and more complex. Due to this complexity of supply chain, Indian manufacturing organisations faces different types of risks associated with their supply chain network. The unpredictable nature of risks, improper evaluation of the impact and selection of imperfect/wrong strategy, in turn, lead to an adverse effect on the performance of the supply chain. Therefore, prioritization of risks is essential for orgnisation to anticipate the unexpected risks. Risks prioritization further helps in providing information about the sources of supply chain risks, the quantum of risks, the probability of occurrence of risks. An efficient SCRM makes organisations more resilience to these risks and also helps them in selecting the most feasible strategy to anticipate the supply chain risks. Large number of supply chain risk variables plays a vital role to make the supply chain robust. It is important for the Indian manufacturing organisation to identify the significant and insignificant risk variables; and prioritize them to make supply chain more robust.

The frame work of prioritization is as follows: In the first step, identify the major risk variables: Literature was reviewed from 20001 to 2019, Supply chain risks, SCRM, AHP, etc. keywords were used to collect the relevant research papers. Only peer-reviewed journals were included in this literature review. Study of all supply chain risks at the same time can make the SCRM model very complex. Accordingly, from literature review and expert opinions, seven major risks, which potentially affect the Indian manufacturing organisation, have been considered. These risk variables are
Environmental risk (ER), Information technology risk (IR), Supply risk (SR), Process risk (PR), Transportation risk (TR), Delay risk (DE), and Demand risk (DR), which are described as follows:

\section{A. Environmental Risk (ER):}

The risks which emerge from outside to the supply chain and affect the supply chain externally are known as external risks such as environmental risk. These risks may directly or indirectly affect supply chain performance. Natural disasters, Extreme weather conditions are the main example of these type of risks. The frequency of these risks are very low but their impact is very severe. Indian manufacturing organisations expand their production facilities at a different location to expand their business expansion or cost-cutting of the product. It may also lead the chances of environmental risks because some area is in the seismic zone (Bhuj, Gujarat), some area is prone to storm (Coastal Areas, etc.), some area is terrorism/Naxalite zone (Jharkhand, Chhattisgarh). These risks have a very high impact on Indian manufacturing supply chain.

\section{B. Information Technology Risk (IR):}

Information technology plays a vital role in supply chain of any organisation. Information management system includes the software as well as hardware failure. Information Technology works as a support system for supply chain and it improves the coordination among the supply chain partners. Hardware/software failure, distortion in information sharing, failure in IT systems, human errors, viruses and malicious attacks are the examples of Information technology risks. It can be managing by continuous risk assessment of information technology system.

\section{Supply Risk:}

Indian manufacturing organisations are more vulnerable with the upstream side (supplier dependent) of their supply chain. As production process, product quality and product cost of the product, etc., are mainly dependent on the quantity, quality, and availability of the supplied raw material, so it is most important for any organisation to focus on their upstream supply chain. Dependency on the key supplier, inflexible supplier capacity, variation in replenishment lead-times, buyer-supplier relationship, quality and cost issues, selection of the wrong supplier, etc. is the main causes for supply chain risks. These risks directly impact on the quality and cost of the final product, which may have a significant effect on the organisation profit.

\section{Process Risk $(P R)$ :}

Process risks are a type of internal risk, which are directly associated with the manufacturing process of the supply chain. These type of risks occurs due to rapid changes in production technologies, machine/material failure, Higher production cost, Manufacturing variability, Demand and supply uncertainty, inflexible manufacturing processes, Limited capacity/bottlenecks, Costs of holding inventories, etc. Process risks also known as production risks, operational risks, etc. 
Good co-ordination between Production manager and SCRM manager can help to better management of these type of risks.

\section{E. Transportation Risk (TR):}

Risks which are associated with the distribution network of the supply chain are known as Distribution risks or Transportation risks. In India, Road and Rail network is the main transportation medium for the movement of goods within the country. Every product has a different nature, so it needs different attention to transport like some product are fragile, some are perishable in nature, etc. Hence, the selection of the right mode of transport is very important for supply managers. Transporter's strikes, limited capacity of transport, higher costs of transportation, cargo Damage/theft, warehouse Inadequacies are the main reasons for disruption in the distribution system.

\section{F. Delay Risk (DE):}

Delay risks are those risks which results delay in the flow of material, information and finance through an organisation's supply chain. These risks may directly or indirectly affect supply chain performance. Excessive handling due to border crossings, port capacity and congestion, long custom clearance process at ports, delay in material or information flow, production failure, supplier's inability to respond quickly to a change in demand are the main example of these type of risks.

\section{G. Demand Risk (DR):}

Demand means to understand, analyse and forecast the right demand at the right time for production, followed by the supply of the right quantity of right quality product at the right time. Demand and supply both are inter-related terms and generally studied simultaneously. Demand risks relate to the disruption occurs from the downstream side (unpredictable nature of customer demand) of the supply chain. The main examples of demand risks are lack of collaborative planning, poor forecasts, bullwhip effects due to multiple echelons, short product life cycles, and lack of SC visibility. If any demand risk occurs, it directly impacts on the demand-supply gap, which leads to detrimental effects on supply chain performance.

\section{RESEARCH METHODOLOGY}

In this section, a research methodology for prioritization of supply chain risks is proposed. Nowadays, Indian manufacturing organisations have so many risk variables associated with their supply chain. Therefore, the prioritization of risk variables is very essential for an organisation.

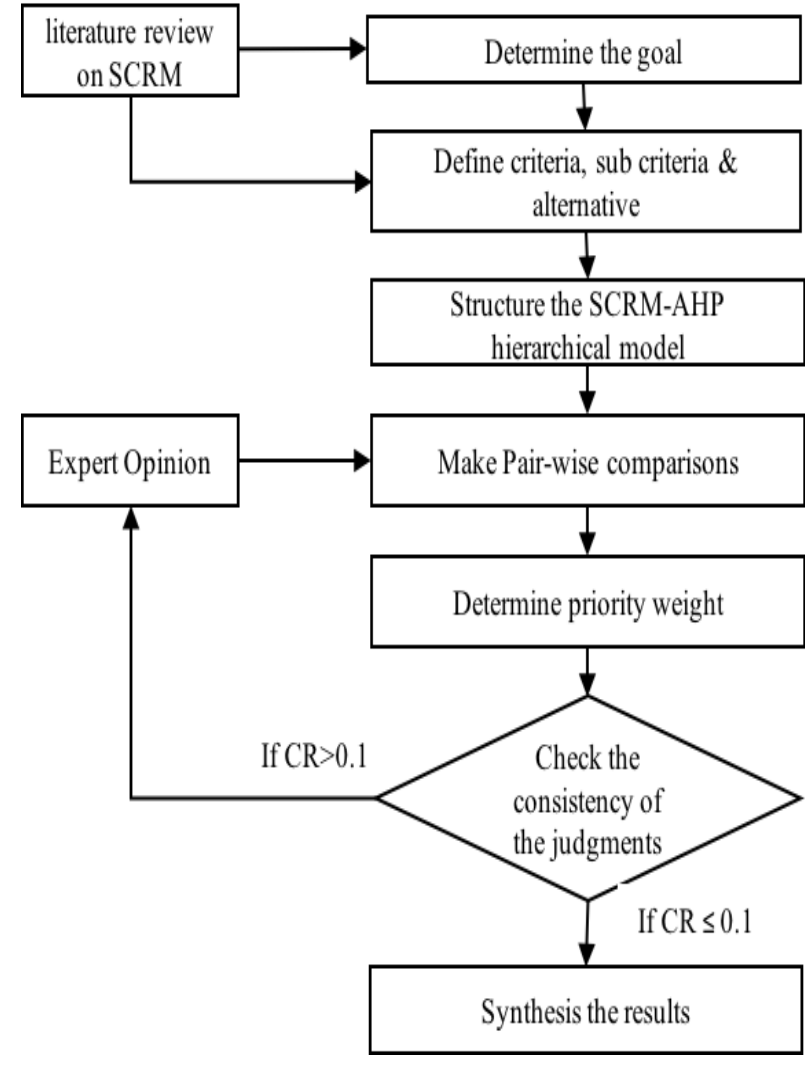

Fig. 1. Research methodology

AHP methodology was developed by [25] It is a multi-criteria decision-making technique, widely used by researchers to find the best alternative by evaluating the criteria and sub-criteria from a given set. This methodology can be used for quantitative as well as qualitative research. AHP converts the empirical data into the mathematical form. It starts with a pair-wise comparison of criteria and sub-criteria and alternatives and based on this comparison, it assigns the weight of each element of the hierarchy. In context to Indian manufacturing organisations, the proposed SCRM-AHP model consists of seven phases as shown in Fig.1. These phases of SCRM-AHP model is summarized as under: -

Step-1. Determine the goal

Step-2. Define criteria, sub criteria and alternative Step-3. Structure the SCRM-AHP hierarchical model Step-4. Make Pair-wise comparisons

Step-5. Determine priority weight

Step-6. Check the consistency of the judgments

Step-7. Synthesis the result

\section{1) Determine the goal:}

In the first step, a comprehensive literature review of SCRM is done. This research paper is based on the last 15 years of articles published in reputed journals. To find the related articles AHP, Supply Chain Risk, Risk Management, SCRM, etc., keywords were used. Inderscience, Emerald, IEEExplore, ScineceDirect, Springer, Wiley and Taylorand Francis etc. academic database were used to consider the journal articles related to SCRM.

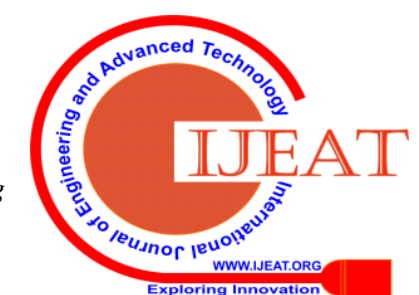


Several criteria and sub-criteria were used to filter the relevant article. The main Goal of this research paper to identify, analyze and prioritize the supply chain risks associated with Indian manufacturing organisations and develop an SCRM-AHP Model.

\section{2) Define criteria, sub criteria and alternative:}

This phase involves defining the criteria, sub-criteria and alternative in order to achieve the desired SCRM goal. Based on the literature review and opinion of Industry experts, seven significant risk variables were identified. All the risk variables are discussed under the section-3. To evaluate these risk variables, five criteria were identified namely; occurrence, severity, detectability of risk, risk management cost, risk controllability.

\section{3) Structure the hierarchical model:}

A hierarchical model is a graphical representation of the objective/Goal, their criteria and sub-criteria (if any), and the alternatives. This model provides a brief summary of the SCRM. This model is comprehensively developed for Indian manufacturing organisation supply chain, and it is based on the literature review of SCRM and Industry expert's opinion. This model is composed of three levels. Prioritization of risk variables is at first level and the five selected criteria are placed at the second level. In the third level of the model, it consists of seven risk variables of Indian manufacturing organisations. Thus SCRM-AHP hierarchical model is structured, which is shown in Fig. 2.

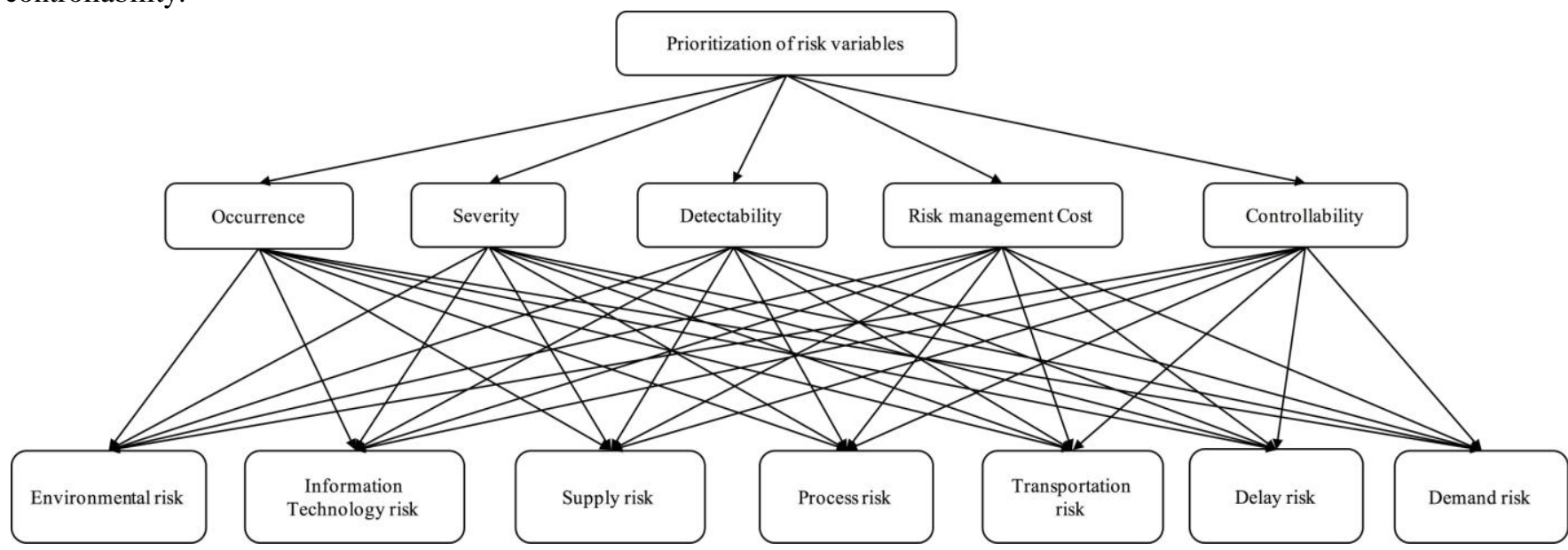

Fig. 2. Structure model for prioritization of risk variables

\section{4) Make Pair-wise comparisons}

After the formation of SCRM-AHP hierarchical model, the next step is to collect the primary data for the evaluation of model elements. Accordingly, a questionnaire was designed by incorporating all the elements of this Model. A 9-point scale rating system was used to analyze and evaluate the risk variables, which is exhibited in Table-I [25]. This questionnaire was used to gather the pair-wise comparison data from the industry experts. A case study was conducted on North India based medium size Indian manufacturing organisation. Due to privacy policy of organisation, the organisation is acknowledged by 'ABC' organisation in the remaining paper. In order to collect pair-wise evaluation of various factors of SCRM, 'ABC' organisation were approached with the questionnaire and pair-wise comparison data collected from the experts of 'ABC' company. The collected pair-wise comparison data were used to determine the normalized weights of each element of the model. This pair-wise comparison data and weights of risk factors were used as an input for the analysis of the next level of this model.

Table I. Saaty Scale of Relative Importance (Saaty, 1980)

\begin{tabular}{|c|l|}
\hline $\begin{array}{c}\text { Numerical } \\
\text { value }\end{array}$ & $\begin{array}{l}\text { Verbal meaning for risk factor evaluation and } \\
\text { for SCRM strategies evaluation }\end{array}$ \\
\hline 1 & Equally important \\
\hline 2 & Equally to moderately more important \\
\hline 3 & Moderately more important \\
\hline 4 & Moderately to strongly more important \\
\hline 5 & Strongly more important \\
\hline 6 & Strongly to very strongly more important \\
\hline
\end{tabular}

\begin{tabular}{|l|l|}
\hline 7 & Very strongly more important \\
\hline 8 & Very strongly to extremely more important \\
\hline 9 & Extremely more important \\
\hline
\end{tabular}

\section{5) Determine priority weight:}

After completing the all pair-wise comparison among all the criteria of the model, next step is to evaluate and establish the relative weights of risk variables. The evaluation of the isk variables was done in analogous to the comparison of risk criteria. These relative weights prioritize the risk variables for better SCRM. Higher the relative weight of risk shows the importance of the risk to achieve the SCRM goal for given problem. Thus this model evaluates all the risk variables and determine their priority weights.

\section{6) Check the consistency of the judgments:}

From AHP methodology, the relative weight of each element is derived from the pair-wise comparison, so it may be inconsistent to a limited extent. Therefore, a consistency test is required to ascertain the consistency of the data. Consistency Ratio (CR) index is widely used to evaluate the consistency of the relative weights. [26] suggested a CR value is equal to 0.10 or less is indicated that the pair-wise comparison data are consistent and acceptable. In this research, it was found that the $\mathrm{CR}$ value of each element is below 0.10 , this shows that the pair-wise comparison data received from the experts were consistent.

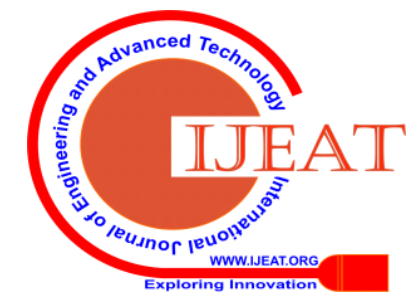


Prioritization of Supply Chain Risks in Indian Manufacturing Context

Table II. Pair wise comparison of criteria $\left(C_{\mathrm{i}}\right)$

\begin{tabular}{|l|c|c|c|c|c|}
\hline & $C_{1}$ & $C_{2}$ & $C_{3}$ & $C_{4}$ & $C_{5}$ \\
\hline Occurrence $\left(C_{1}\right)$ & 1.00 & 0.33 & 3.00 & 5.00 & 5.00 \\
\hline Severity $\left(C_{2}\right)$ & 3.00 & 1.00 & 5.00 & 5.00 & 5.00 \\
\hline Detectability $\left(C_{3}\right)$ & 0.33 & 0.20 & 1.00 & 1.00 & 1.00 \\
\hline Cost $\left(C_{4}\right)$ & 0.20 & 0.20 & 1.00 & 1.00 & 1.00 \\
\hline Controllability $\left(C_{5}\right)$ & 0.20 & 0.20 & 1.00 & 1.00 & 1.00 \\
\hline
\end{tabular}

Table III. Pair-wise comparison of risk variables w.r.to Occurrence $\left(C_{1}\right)$

\begin{tabular}{|l|c|c|c|c|c|c|c|}
\hline & ER & IR & SR & PR & TR & DE & DR \\
\hline ER & 1.00 & 3.00 & 7.00 & 7.00 & 3.00 & 3.00 & 3.00 \\
\hline IR & 0.33 & 1.00 & 5.00 & 5.00 & 1.00 & 3.00 & 3.00 \\
\hline SR & 0.14 & 0.20 & 1.00 & 1.00 & 0.20 & 0.33 & 0.33 \\
\hline PR & 0.14 & 0.20 & 1.00 & 1.00 & 0.20 & 0.33 & 0.33 \\
\hline TR & 0.33 & 1.00 & 5.00 & 5.00 & 1.00 & 3.00 & 3.00 \\
\hline DE & 0.33 & 0.33 & 3.00 & 3.00 & 0.33 & 1.00 & 1.00 \\
\hline DR & 0.33 & 0.33 & 3.00 & 3.00 & 0.33 & 1.00 & 1.00 \\
\hline
\end{tabular}

Table IV. Pair-wise comparison of risk variables w.r.to Severity $\left(C_{2}\right)$

\begin{tabular}{|l|c|c|c|c|c|c|c|}
\hline & ER & IR & SR & PR & TR & DE & DR \\
\hline ER & 1.00 & 1.00 & 3.00 & 1.00 & 0.20 & 0.33 & 3.00 \\
\hline IR & 1.00 & 1.00 & 3.00 & 1.00 & 0.33 & 0.33 & 1.00 \\
\hline SR & 0.33 & 0.33 & 1.00 & 0.33 & 0.33 & 0.20 & 3.00 \\
\hline PR & 1.00 & 1.00 & 3.00 & 1.00 & 0.33 & 0.33 & 3.00 \\
\hline TR & 5.00 & 3.00 & 3.00 & 3.00 & 1.00 & 1.00 & 5.00 \\
\hline DE & 3.00 & 3.00 & 5.00 & 3.00 & 1.00 & 1.00 & 5.00 \\
\hline DR & 0.33 & 1.00 & 0.33 & 0.33 & 0.20 & 0.20 & 1.00 \\
\hline
\end{tabular}

Table V. Pair-wise comparison of risk variables w.r.to Detectability $\left(C_{3}\right)$

\begin{tabular}{|l|c|c|c|c|c|c|c|}
\hline & ER & IR & SR & PR & TR & DE & DR \\
\hline ER & 1.00 & 5.00 & 3.00 & 5.00 & 5.00 & 3.00 & 3.00 \\
\hline IR & 0.20 & 1.00 & 0.33 & 1.00 & 3.00 & 0.33 & 0.33 \\
\hline SR & 0.33 & 3.00 & 1.00 & 3.00 & 3.00 & 3.00 & 3.00 \\
\hline PR & 0.20 & 1.00 & 0.33 & 1.00 & 3.00 & 0.33 & 0.33 \\
\hline TR & 0.20 & 0.33 & 0.33 & 0.33 & 1.00 & 0.33 & 0.33 \\
\hline DE & 0.33 & 3.00 & 0.33 & 3.00 & 3.00 & 1.00 & 1.00 \\
\hline DR & 0.33 & 3.00 & 0.33 & 3.00 & 3.00 & 1.00 & 1.00 \\
\hline
\end{tabular}

Table VI. Pair-wise comparison of risk variables w.r.to

Cost $\left(C_{4}\right)$

\begin{tabular}{|l|c|c|c|c|c|c|c|}
\hline & ER & IR & SR & PR & TR & DE & DR \\
\hline ER & 1.00 & 1.00 & 0.33 & 5.00 & 3.00 & 3.00 & 5.00 \\
\hline IR & 1.00 & 1.00 & 0.33 & 3.00 & 0.33 & 5.00 & 5.00 \\
\hline SR & 3.00 & 3.00 & 1.00 & 5.00 & 1.00 & 5.00 & 5.00 \\
\hline PR & 0.20 & 0.33 & 0.20 & 1.00 & 0.33 & 1.00 & 1.00 \\
\hline TR & 0.33 & 3.00 & 1.00 & 3.00 & 1.00 & 3.00 & 3.00 \\
\hline DE & 0.33 & 0.20 & 0.20 & 1.00 & 0.33 & 1.00 & 3.00 \\
\hline DR & 0.20 & 0.20 & 0.20 & 1.00 & 0.33 & 0.33 & 1.00 \\
\hline
\end{tabular}

Table VII. Pair-wise comparison of risk variables w.r.to Controllability $\left(C_{5}\right)$

\begin{tabular}{|l|c|c|c|c|c|c|c|}
\hline & ER & IR & SR & PR & TR & DE & DR \\
\hline ER & 1.00 & 3.00 & 5.00 & 3.00 & 5.00 & 5.00 & 3.00 \\
\hline IR & 0.33 & 1.00 & 3.00 & 1.00 & 3.00 & 3.00 & 3.00 \\
\hline SR & 0.20 & 0.33 & 1.00 & 0.33 & 1.00 & 1.00 & 3.00 \\
\hline PR & 0.33 & 1.00 & 3.00 & 1.00 & 3.00 & 3.00 & 3.00 \\
\hline TR & 0.20 & 0.33 & 1.00 & 0.33 & 1.00 & 1.00 & 3.00 \\
\hline DE & 0.20 & 0.33 & 1.00 & 0.33 & 1.00 & 1.00 & 1.00 \\
\hline DR & 0.33 & 0.33 & 0.33 & 0.33 & 0.33 & 1.00 & 1.00 \\
\hline
\end{tabular}

Table VIII. Priority weights for each criterion

\begin{tabular}{|l|c|}
\hline & Priority weight \\
\hline Occurrence $\left(C_{1}\right)$ & 0.275 \\
\hline Severity $\left(C_{2}\right)$ & 0.384 \\
\hline Detectability $\left(C_{3}\right)$ & 0.078 \\
\hline Cost $\left(C_{4}\right)$ & 0.185 \\
\hline Controllability $\left(C_{5}\right)$ & 0.078 \\
\hline
\end{tabular}

Table IX. Priority weights and ranking of each risk variables

\begin{tabular}{|l|c|c|}
\hline & Priority weight & Rank \\
\hline Environmental risk & 0.219 & 1 \\
\hline Information technology risk & 0.188 & 2 \\
\hline Supply risk & 0.154 & 3 \\
\hline
\end{tabular}

\begin{tabular}{|l|l|l|}
\hline Demand risk & 0.151 & 4 \\
\hline Transportation risk & 0.141 & 5 \\
\hline Process risk & 0.082 & 6 \\
\hline Delay risk & 0.065 & 7 \\
\hline
\end{tabular}

\section{7) Synthesis the result:}

After evaluating the consistency of relative weights, the next step is to synthesize the model results. This step is used to understand the significance and contribution of each element to achieve the objective of the model. The main objective of this research to prioritize the risks w.r.to different criteria of Indian manufacturing organisations. Results of this model are useful to understand the major risks, as well as help in preparing the anticipation strategies, which may improve the supply chain performance of the organisation. The AHP results are provided in Table VIII and IX. Result of this model proves that the Environment risk (0.219) and Information technology risk (0.188) are most critical risks. Therefore, supply chain managers have to be very careful while dealing with these risk variables and to anticipate these risks by sharing the information to the upstream and downstream partners of supply chain. The result of this model also confirm that Supply risk (0.154), Demand risk (0.151) and Transportation risk (0.141) have moderate impact on supply chain. Process Risk (0.082) and Delay Risk (0.065) are least ranked risks. These results will help the supply chain managers to prioritize the risk variables during implementation of SCRM.

\section{RESULT AND DISCUSSION}

In the literature, large number of risk variables are identified by researchers, but after discussion with industry experts, only seven significant risk variables are considered for development of this model. The relative weight of these risk variables has been obtained with the help of the AHP approach. It reveals the importance of assessment and prioritization of supply chain risks for Indian manufacturing organisations. This model will provide a guideline to supply chain managers for prioritization of risk variables while allocating resources to anticipate them. In this research, five criteria were used to evaluate the risks variables. Table VIII exhibit the weightage of each criteria, severity (0.384) have highest weightage and detectability (0.078) have lowest weightage. Table IX shows the priority weight and rank of

each risk variable for environmental risk. Environment risk (0.219) and Information technology risk (0.188) are perceived as the most critical risks for an Indian Manufacturing organisation. These data and its analysis will assist managers to understand and overcome the supply chain risks.

\section{CONCLUSION AND MANAGERIAL IMPLICATIONS}

Supply chain managers have to consider these results during implementation of SCRM in Indian Manufacturing Organisation. It will also help them to select the most suitable SCRM strategy.

Published By:

Blue Eyes Intelligence Engineering

\& Sciences Publication

(C) Copyright: All rights reserved. 
These results also provide a guideline to managers that which risks they should give high importance and which risks to give the least concern for effective risk management in the supply chain. This research mainly focuses on supply chain risk management in the Indian Manufacturing context only. This research brings novelty by analyzing all five evaluation criteria used in the evaluation of risk management. In this research only seven risk factors considered related to an Indian manufacturing organisation, this model can also be further extended by the addition of more risks and sub-risks.

Indian manufacturing supply chain networks are very complex, and they have limited resources to manage it. In this study, An AHP model is developed to evaluate and prioritize the risk variables, which would help the supply chain managers to optimally allocate its resources to improve its supply chain performance. These results will help to supply chain managers in decision making in Indian manufacturing context as a guideline for implementing SCRM. Further, these findings would help other organisations/industries to design their SCRM model for mitigating various risk variables.

\section{REFERENCES}

1. Knemeyer, A. M., Zinn, W., and Eroglu, C. (2009). Proactive planning for catastrophic events in supply chains. Journal of operations management, 27(2), 141-153.

2. Millet, I., and Wedley, W. C. (2002). Modelling risk and uncertainty with the analytic hierarchy process. Journal of Multi-Criteria Decision Analysis, 11(2), 97-107.

3. Blackhurst, J. V., Scheibe, K. P., and Johnson, D. J. (2008). Supplier risk assessment and monitoring for the automotive industry. International Journal of Physical Distribution and Logistics Management, 38(2), 143-165.

4. Gaudenzi, B., and Borghesi, A. (2006). Managing risks in the supply chain using the AHP method. The International Journal of Logistics Management, 17(1), 114-136.

5. Mishra, S., Raut, R. D., Narkhede, B. E., Gardas, B. B., and Priyadarshinee, P. (2018). To investigate the critical risk criteria of business continuity management by using analytical hierarchy process. International Journal of Management Concepts and Philosophy, 11(1) 94-115.

6. Hachicha, W., and Elmsalmi, M. (2014). An integrated approach based-structural modeling for risk prioritization in supply network management. Journal of Risk Research, 17(10), 1301-1324.

7. Radivojević, G., and Gajović, V. (2014). Supply chain risk modeling by AHP and Fuzzy AHP methods. Journal of Risk Research, 17(3), 337-352.

8. Standard, B. BS 4778 (1991): Glossary of terms used in quality assurance (including reliability and maintainability). British Standards Institution, London.

9. Christopher, M., and Peck, H. (2004). Building the resilient supply chain. The international journal of logistics management, 15(2), 1-14.

10. Yang, B., and Yang, Y. (2010). Postponement in supply chain risk management: a complexity perspective. International Journal of Production Research, 48(7), 1901-1912.

11. Faisal, M. N., Banwet, D. K., and Shankar, R. (2007). Quantification of risk mitigation environment of supply chains using graph theory and matrix methods. European Journal of Industrial Engineering, 1(1), 22-39.

12. Manuj, I., and Mentzer, J. T. (2008). Global supply chain risk management strategies. International Journal of Physical Distribution and Logistics Management, 38(3), 192-223.

13. Wu, T., and Blackhurst, J. V. (Eds.). (2009). Managing supply chain risk and vulnerability: tools and methods for supply chain decision makers. Springer Science and Business Media.

14. Tang, O., and Musa, S. N. (2011). Identifying risk issues and research advancements in supply chain risk management. International journal of production economics, 133(1), 25-34.

15. Diabat, A., Govindan, K., and Panicker, V. V. (2012). Supply chain risk management and its mitigation in a food industry. International Journal of Production Research, 50(11), 3039-3050.
16. Kumar Sharma, S., and Bhat, A. (2014). Supply chain risk management dimensions in Indian automobile industry: A cluster analysis approach. Benchmarking: An International Journal, 21(6), 1023-1040.

17. Micheli, G. J., Mogre, R., and Perego, A. (2014). How to choose mitigation measures for supply chain risks. International Journal of Production Research, 52(1), 117-129.

18. Kumar Pradhan, S., and Routroy, S. (2014). Analyzing the supply chain risk issues for an Indian manufacturing company. Journal of Advances in Management Research, 11(2), 144-162.

19. Mangla, S. K., Kumar, P., and Barua, M. K. (2015). Risk analysis in green supply chain using fuzzy AHP approach: A case study. Resources, Conservation and Recycling, 104, 375-390.

20. Ho, W., Zheng, T., Yildiz, H., and Talluri, S. (2015). Supply chain risk management: a literature review. International Journal of Production Research, 53(16), 5031-5069.

21. Gandhi, S., Mangla, S. K., Kumar, P., and Kumar, D. (2016). A combined approach using AHP and DEMATEL for evaluating success factors in implementation of green supply chain management in Indian manufacturing industries. International Journal of Logistics Research and Applications, 19(6), 537-561.

22. Min, H., Park, H., and Ahn, S. B. (2017). Measuring the supply chain risk in offshoring countries using data envelopment analysis and the analytic hierarchy process. Benchmarking: An International Journal, 24(7), 1977-1994.

23. Mishra, S., Raut, R. D., Narkhede, B. E., Gardas, B. B., and Priyadarshinee, P. (2018). To investigate the critical risk criteria of business continuity management by using analytical hierarchy process International Journal of Management Concepts and Philosophy, 11(1), 94-115.

24. Gautam, A., Prakash, S., and Soni, U. (2018). Supply chain risk management and quality: a case study and analysis of Indian automotive industry. International Journal of Intelligent Enterprise, 5(1-2), 194-212.

25. Wind, Y., and Saaty, T. L. (1980). Marketing applications of the analytic hierarchy process. Management science, 26(7), 641-658.

26. Saaty, T. L. (1990). How to make a decision: the analytic hierarchy process. European journal of operational research, 48(1), 9-26.

\section{AUTHORS PROFILE}

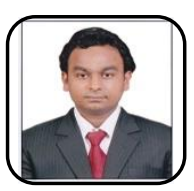

Harish Babu is a Research Scholar in the Department of Mechanical Engineering at Indian Institute of Technology (Banaras Hindu University), Varanasi, India. He received his Master of Business Administration degree from Graphic Era University Dehradun. He has more than 5 years of experience in teaching and research. His areas of research interest are Supply Chain Risk Management and Materials Management.

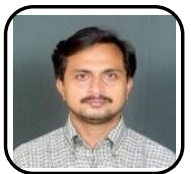

Prabhas Bhardwaj is a Professor in the Department of Mechanical Engineering at Indian Institute of Technology (BHU), Varanasi, India. He obtained his B.Sc Engineering in Mechanical Engineering and M.Tech. in Engineering Systems and Management from Dayalbagh Educational Institute, Agra and $\mathrm{PhD}$ from Indian Institute of Technology (BHU), Varanasi. He has more than 20 years of experience in teaching and research. He has publications in peer-reviewed international journals. His current area of research includes Industrial Management, Supply Chain Management, Cellular Manufacturing System, Simulation methodology in manufacturing system design and analysis, Engineering Economics, Quality Engineering, OR, PPC.

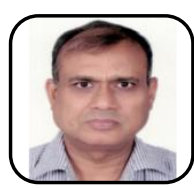

Anil Kumar Agrawal is a Professor in the Department of Mechanical Engineering at Indian Institute of Technology (BHU), Varanasi, India. He has more than 30 years of experience in teaching and research. He has publications in peer-reviewed international journals. His current area of research includes Quality Control, Six Sigma, Optimization, Industrial Engineering, Operation Management, Supply Chain Management.

Published By:

Blue Eyes Intelligence Engineering DOI: 10.35940/ijeat.C6378.049420

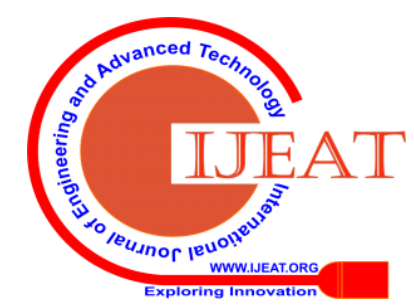

